\title{
A STUDY OF AMATEUR GROUPS' RE-INTERPRETATION OF TRADITIONAL DANCES IN GHANA: ROLE ON CONTINUITY AND SAFEGUARDING ${ }^{1}$
}

\author{
Eric Baffour AwuAH \\ Choreomundus - International Master in Dance Knowledge, Practice and Heritage \\ Vida Asare Bediannco, U.G. B.S. Box LG 78, University of Ghana \\ E-mail: awuah47@gmail.com
}

\begin{abstract}
The amateur dance category in Ghana has been a vibrant force in the performance of traditional Ghanaian dancing for over 20 years. Fluid in ideologies, they have been able to affect the paradigms of traditional dancing in Ghana so much that their activities cannot be overlooked. Even though they are mostly taunted as the 'destroyers' of traditional forms by some schools of thought, this category's input is especially important as they have a direct influence on dance structures in Ghana through their re-interpretations of traditional dance forms. This paper seeks to identify some distinctive re-interpretative styles/patterns this category exerts on traditional dances and their effects on preservation of traditional dances in Ghana.
\end{abstract}

Keywords: traditional dance, Ghana, safeguarding, continuity

\section{INTRODUCTION}

To speak of the amateur dance category or various amateur dance groups in Ghana as a group of dance practitioners with the same practices or ideologies as is mostly done in Ghana will be like to pour water in a basket with the aim of storage - it simply cannot hold. Due to the limited research into the very structures and practices of the amateur dance category ${ }^{2}$, empirical evidence has given way to generalizations and stereotypes in this category so much that it is undermining their contributions (good or bad). Therefore to individualise a diverse category such as that of the amateurs in Ghana as one generic whole will be to devoid researchers the opportunity to unravel the different layers/com-

${ }^{1}$ This paper is a section of an unpublished master thesis with the same title.

${ }^{2}$ Prior to the research I divided the main practitioners of traditional dancing in Ghana into four (4) categories. They are the Traditional category (the creators of the traditional form who are located in the traditional settings), Professional category (The Ghana Dance Ensemble), Academic category (the School of Performing Arts, University of Ghana), and the Amateur category (dance groups who are not affiliated to any institutions like the professional and the academic). 
plexities of this category, their use of traditional material, and their ways of presentation of the material in the $21^{\text {st }}$ century. Largely situated in the capital city of Accra, dance groups found within this category treat traditional materials such as music and dance subjectively as I observed from two dance groups in the summer of 2013. I have come to realise that the uniqueness of each individual amateur group contributes to the exploration and re-thinking of concepts of what makes up Ghanaian dance movements, neo-traditional dances $^{3}$, and dance contextualisation. This is because a style of treatment of a traditional dance form by an amateur dance group might either complicate an underdeveloped theory of traditional dance transmission in Ghana or produce insights into carefully identifying new discoveries through research about our evolving dance practices and their roles in development. The amateur category in Ghana has drawn upon from the experimentations with traditional forms by the Ghana Dance Ensemble of the University of Ghana. Set up in 1962, the ensemble was charged with the research and development of traditional dance forms in Ghana. ${ }^{4}$ The ensemble's influence and treatment of traditional dances have opened the way for a generation of practitioners like dance groups from the amateur category to appropriate the ideas of the ensemble. Most dance groups have also gone far to emulate their very physical structures either administrative or dance-wise.

Following in the footsteps ${ }^{5}$ of the Ghana Dance Ensemble (GDE), most dance groups in the amateur dance category have also altered performance paradigms in their own unique way. To identify some characteristic treatments of traditional materials, this paper discusses how two amateur dance groups operate; their totality as an existing body of dancers and the influences that affect their performances of traditional dance forms.

\section{A LOOK INTO AN AMATUER GROUP IN GHANA}

There are ideologies that were employed in the appropriation of traditional materials by the professional and academic categories and also there are other similar ideologies dance groups in the amateur category follow. Appropriation as a process of 'editing' specific dances by these categories have all affected traditional dancing in unique ways. These can be identified by juxtaposing and contrasting, by analysis, the extent to which our traditional dance forms serve our past and current needs. As Jane Desmond aptly puts it in her elaboration on her appropriation concept, when she posits that

in studying the transmission of a form, it is not only the pathway of that transmission, but also the form's re-inscription in a new community/social context and

\footnotetext{
${ }^{3}$ Neo-traditional dances according to Kariamu Welsh and Elizabeth Hanley are dances that are created in the likeness of traditional dances and are not bound to all aesthetics and cultural rules of the society (WELSH - HANLEy 2010: 18).

${ }^{4}$ AdinKu 1994.

${ }^{5}$ Footsteps here do not include the specific reasons for setting up the ensemble within the pan-Africanist era in the history of Ghana or as a move to identify through research the traditional forms and develop them, help in reversing the colonial effects on traditional forms, etc. Footsteps here rather connote the interpretations of traditional forms like dance and their varied styles of performances on a theatre stage.
} 
resultant changes in its signification that is important to analyse. An analysis of appropriation must include not only the transmission pathway and the mediating effects of the media, immigration patterns, and the like, but also an analysis at the level of the body of what changes in this transmission. ${ }^{6}$

Therefore, a study into the 're-interpreted' traditional dance forms by the amateur category in Ghana can provide an insight into the significant changes within this dancing community, which is paramount in helping to understand their influence on neo-traditional dancing. Whereas the professional category (GDE) is guided by experimentations influenced by the theatre stage (be it proscenium, arena, or end stages, etc.), the amateur category is perhaps also influenced by experimentations based on 'make-shift' stages (mostly outside the theatre), aesthetics, ${ }^{8}$ and survival. ${ }^{9}$ For example, neo-traditional dance forms created through a deductive selection methodology employed by the first artistic director of the GDE hinged on the conventions and influence of the proscenium stage but, that notwithstanding, movements stayed as close to the material as possible even in their 'new' representation formats. ${ }^{10}$ David Quaye a lecturer at the University of Ghana affirms that

Opoku ${ }^{11}$ was very much careful not to destroy the content and context of the dance but to present them in a more artistic setting [...] being a choreographer himself (he) understood the meaning of the movement and gestures, therefore addition and subtraction of movements were done with much care so as not to change the dance and its meaning. ${ }^{12}$

However, most of the amateur groups who practice the choreographed versions from the GDE are oblivious of the fact that the dance structures they borrow from the ensemble are experimentations that do not entirely conform to the tradition but are influenced by virtue of the artistry and political position of the ensemble's dwelling within academia.

There are varied reasons for performing neo-traditional Ghanaian dances by amateur groups in Ghana. As a participant observer with various encounters with various amateur groups, I have the impression that for most groups in this category, traditional forms are either for economic survival or for the continuity of culture. First, to be recognised as a dance group in Ghana or in Accra to be precise, one must at least have a good repertoire of traditional dances to attain a level of respect and assistance (like borrowing of drums and

\footnotetext{
${ }^{6}$ Desmond 1993: 39.

7 'Re-interpreted' in the sense that most amateur groups alter the already altered dances by the Ghana Dance Ensemble, hence the use of this term.

${ }^{8}$ Aesthetics based on the likeness of what is seen physically rather than underlying meanings of movements that supports most traditional dance movements in Ghana. Most amateur groups are influenced more by beauty than reason and this affects their interpretations of traditional materials in a way.

${ }^{9}$ Survival as in subsistence.

${ }^{10}$ William Diku: The Bawa Dance. Interviewed by Eric Baffour Awuah [in person], University of Ghana, Legon, $15^{\text {th }}$ August 2013. William Diku is a retired principal dancer of the GDE.

${ }^{11}$ Professor Mawere Opoku was the first artistic director of the Ghana Dance Ensemble.

${ }^{12}$ Quaye 2011: 106-107.
} 
getting help from other groups for performances in the case of short staffing, etc.) from other dance groups. In several interviews, many amateur group leaders and dancers seem to agree that it is through the traditional dance forms predominantly that most amateur groups survive financially through performance gigs. In an interview with Gasko Atsu Ablordey the leader of the Dagbeneva Dance Theatre, ${ }^{13}$ he explains to $\mathrm{me}^{14}$ that "the performances give us small monies to survive"15 (personal interview, 2010). Secondly, on the continuity of culture reason, it might be as a result of either a moral or traditional obligation of being a traditional dance group in Accra that compels most amateur groups to propagate the traditional forms from the myriad of cultures in Ghana for posterity through constant performances.

\section{CHARACTERISTICS OF AN AMATEUR DANCE GROUP IN GHANA: A STUDY \\ OF THE AGBE MUSIC AND DANCE OF AFRICA AND THE DAGBENEVA DANCE THEATRE GROUPS}

To identify a dance group within the amateur category, one must become aware of not only the physical appearance but also of their locations, performance ethics, ${ }^{16}$ dedication to dancing, and peculiarity of dance presentation ${ }^{17}$ among others. For an inquiry into an amateur group in Ghana, two groups were studied during my summer research period in Ghana in the year 2013. The groups are the Agbe Music and Dance of Africa group (to be referred to by the acronym AMDA) and the Dagbeneva Dance Theatre group (DDT). These two groups at the time of research were located in one of the most densely populated slum areas ${ }^{18}$ known as Maamobi-Nima in Accra-Ghana. Densely populated areas are typical locations of most amateur dance groups in Accra, the capital city of Ghana, which is mostly associated with this category. Both groups are made up of only male dancers and musicians who perform mostly traditional dances from Ghana.

${ }^{13}$ Dagbeneva Dance Theatre is one of the amateur groups used in this research.

${ }^{14}$ I was a guest performer of the group at a wedding ceremony in 2010 - One of my many performances with that particular group.

${ }^{15}$ Dance as a source of financal support for most amateur groups in Accra. Interviewed by Eric Baffour Awuah [in person], Pantang, Accra, $5^{\text {th }}$ March 2013.

${ }^{16}$ Performance ethics as explained by Terry Bright Ofosu, a lecturer at the Dance Department, School of Performing Arts, are stage etiquettes that dancers have to conform to whilst performing; like no talking, full concentration, and good personal hygiene, which he claims most amateur groups in Ghana lack. This in my opinion is relative unless proven beyond doubt by more research.

${ }^{17}$ Which without a closer look is similar to that of professional category albeit their contrasting ideologies for performing traditional dances and use of movements.

${ }^{18}$ The slum here connotes areas in Accra-Ghana that have clustered housing as well as work places of certain jobs found all together in one location. Here, one can find scantily put-up structures that house people and business alike and often do not have social amenities and necessities like running water, schools, electricity, etc. 


\section{HIERARCHY}

Both groups have one founder/leader as is typical in most amateur groups in Ghana. In most cases the leaders act as the choreographers, master drummers, and costume designers. He is assisted by assistant master drummers who take charge of some delegated responsibilities from time to time. The leader negotiates performance deals, group transportation, and monetary payments to members after performances. The leader also serves as the 'problem solver' or the psychologist of the group and provides a helping hand to all members in need, like taking ill members to the hospital, providing food to members and sometimes contributing monies to members' wards education, etc. to mention a few. ${ }^{19}$ (Terry Bright Ofosu 2013, personal interview ${ }^{20}$ )

\section{REHEARSAL STRUCTURE}

Typically, a dance rehearsal lasts for a maximum of two to three hours a day for three times a week by both groups. In the AMDA group each rehearsal begins with a session of drum music followed by a 'Christian' prayer. ${ }^{21}$ This prayer is moderated by any member of the group and his task in this role of supplication is to entrust the rehearsal session to God (Christian specifically) to ensure that all proceedings go well and according to plan. The function of the prayer is to create an atmosphere of godliness and instil a level of good character within all members to ensure a successful rehearsal run. The selection on what dances to rehearse for a night is dependent on whether the group has an upcoming gig or not and thus the final word on selected dances is given by the leader. The mood of the members determines the break intervals between dances and rehearsals are open for the public to observe.

\section{RECRUITMENT INTO THE AMDA AND DDT GROUPS}

These groups like many others in this category have no fixed recruitment policies. Within the AMDA there is no formal auditioning format and thus acceptance is based on whether you are willing to learn quickly or whether the group leader likes you. The two groups have a reputation for not being discriminatory and thus if one shows interest in joining to any group and depending on that individual's interest in drumming or dancing, one is not rejected based on ethnicity or physical features. So far as one is willing to learn quickly, one can become a member of the group and when one has achieved a status fit

\footnotetext{
${ }^{19}$ Terry Bright Ofosu: Performance Ethics. Interviewed by Eric Baffour Awuah [in person], University of Ghana, Legon, $27^{\text {th }}$ August 2013.

${ }^{20}$ Personal interview with Terry Bright Ofosu, a lecturer at the Dance Department, University of Ghana, Legon, about the administrative structures of an amateur group in Ghana.

${ }^{21}$ This is not generic of all amateur groups in the area or even in the whole of Ghana. It is agreed on by mutual consensus.
} 
for public performance with the seniors, one's training is tested. ${ }^{22}$ The DDT has the same recruitment style as the AMDA and I also learned upon enquiry that there is no payment of dues by members to keep the group financially stable.

\section{TRAINING}

In the AMDA group, new and old members mostly go through the 'follow the leader' dance transmission process as I observed. This is a teaching/training style where a leader/ choreographer mostly does not necessarily break down and explain movements in their teaching processes but members are rather required to observe and follow his every move and replicate to the best of their abilities. A typical teaching style within the AMDA and most amateur groups in Ghana has the leader in front of the group executing bodily movements as well as verbalizing (using of counts and/or specific vernacular jargon which are peculiar to the members or combining both) movements for dancers to copy. For example, in teaching certain feet movements, the choreographer uses drum jargons like 'ta tata' to tell his dancers to switch weight, from one leg to the other, from the left to the right foot and then back to the left foot. So ' $t a, t a$, $t a$ ' will translate as 'left, right, left' in verbal lingo. ${ }^{23}$ This style of transmission is typical to most dance groups within the amateur category.

\section{RE-INTERPRETATION OF TRADITIONAL DANCES}

Having observed the amateur category for a while now, even before my research in the summer of 2013 I had come to identify a concept upon which the appropriation of traditional forms from the GDE and the traditional settings are re-interpreted. This is the concept of radical interpretation. Radical interpretation is a process where there is a conscious or unconscious transposition of different movement patterns belonging to other traditional dance forms that may or may not bear any similarities in ideology or movements to a dance form in question but are used anyway in any context. To demonstrate this concept, I will discuss a phenomenon I observed during summer fieldwork. First, it must be understood that any movement in any traditional dance in Ghana, even if not self-explanatory on its own, forms part of a group of complex gestural patterns that communicate a message(s). Therefore if any transposition of movements to another traditional dance form is done, one must consider the implications of such an action on the outlook of the dance in the light of continuity and safeguarding of such dance's future. This is because if this practice is not checked, most traditional dances performed by some amateur dance groups may look different and far from what it is supposed to look like as compared to that of the traditional settings. If this is allowed to continue in Ghana without any research, what will be the reference points upon which to analyse changes in our traditional forms

\footnotetext{
${ }^{22}$ Abgeya Kuwornu: Recruitment into the Agbe Music and Dance of Africa Group. Interviewed by Eric Baffour Awuah [in person], Maamobi-Nima, 16 ${ }^{\text {th }}$ August 2013.

${ }^{23}$ Appendix-video 10/7/2013 - Available online: http://youtu.be/NjtTn1OfA2o
} 
for posterity? I have found this concept to be a recurring style of appropriation among most amateur groups I worked with. For example, in the $B a w a^{24}$ dance of the Upper West Region of Ghana, the GDE has reworked and shortened the whole dance into nine (9) sequential movement stanzas to music. The ensemble's rendition of the Bawa dance has been appropriated by most amateur groups in Ghana and as such most of them even perform same patterns of the ensemble's or little altered versions. The traditional versions ${ }^{25}$ performed in the traditional settings are not very popular in the amateur category and as such most dance groups rely mostly on the ensemble's rendition. ${ }^{26}$ In the DDT's reinterpretation of the dance based on the GDE structure, I noticed some very interesting additions. Even though the music stayed unchanged, stanza 9 for example was noticeably different. In their stanza 9, this group transposed a sequence from another dance from the north of Ghana known as Woungo (specifically from the Upper East Region of Ghana). In terms of safeguarding, this can be harmful to a dance's continuity in that to totally replace variations of the Bawa dance choreographed by the ensemble might not serve the purpose of contributing to the total meaning of the dance. This I believe affects the continuity of the dance through the continual performance of the radically interpreted versions and thus subsequently affects the safeguarding of this dance and other experimented on dance forms.

\section{CONCLUSION}

There are varied reasons and ways traditional dances are appropriated in Ghana. The influence of the GDE's experimentation of the traditional forms provides an insight into the reasons for changes made on such dances (reasons of performance on the proscenium stage). Some dance groups within the amateur category have taken the appropriation a step further and have included direct transpositions of other dances by either replacing or editing the forms to suit their activities. This is one of the reasons why the researcher set out to identify the structures of the amateur categories and the ideologies behind their activities, to identify their effects on the continuity of the traditional dance forms in Ghana. The influences of locations, amenities for rehearsals and creativity, and monetary support have all affected the amateur category so much that it provides an insight into the acts of transposition. With the aim of safeguarding, it is imperative to study the problem state-

\footnotetext{
${ }^{24}$ Bawa is a dance from the Upper West Region of Ghana. It is a harvest dance of the Dagomba people of the region. The Bawa dance was introduced to the ensemble in 1969 and the version created out of the tradition setting by the GDE we see today has come to overshadow the Bawa dance from the indigenous people from the north of Ghana.

${ }^{25}$ This is because the region where the dance originates from has various villages performing the dances in their own ways. What the first artistic director of the ensemble did was select specific movements from selected villages and put them together as the dance. This is perhaps due to the fact that the ensemble could not represent the whole region's dances on stage and thus a selection of specific movements peculiar to selected villages were rather used. The problem here is that most amateur groups in Accra-Ghana do not know this reason and the fact that they might not be performing the traditional versions and thus they even go ahead to claim authenticity and subsequently alter the dance when they want to.
}

${ }^{26}$ AwUah 2013b. 
ment and contribute to alternative solutions which would be more suitable for the aim within this category to help in the overall development of traditional dance studies in Ghana. This paper thus provided specific structures of the category and therefore challenges more research into the category to analyse the changes of our traditional dance forms and how they survive.

\section{APPENDIX}

A link to the Bawa dance as performed by the GDE. The stanza 9 in question is between 09:03-09:20 (http://www.youtube.com/watch?v=psRn-InbdOY).

\section{LITERATURE}

AdiNKu, W. O.

1995: African Dance Education in Ghana. Ghana: Universities Press.

AwUAh, E. B.

2013a: Movement Transmission in the AMDA Group. [video online] Available at: http://youtu.be/ NjtTn1OfA2o [Accessed: 30 Dec 2013].

2013b: A Study of Amateur Groups' Re-Interpretation of Traditional Dances in Ghana: Role on Continuity and Safeguarding. Unpublished thesis, Choreomundus consortium.

Desmond, J. C.

1993: Embodying Difference: Issues in Dance and Cultural Studies. Cultural Critique 26, 33-63.

QuAYe, E. A. David

2011: Analysing the Traditional Dance on Stage within the University: In Close Reference to Opoku's Legacy. Journal of Performing Arts 4(2), 106-107.

Welsh, K. - Hanley, E. A. (eds.)

2010: African Dance. Google Scholar Edition, Chelsea: Infobase Publishing, 18. 